\title{
Learning through a cluster approach: lessons from the implementation of six Australian tourism business sustainability programmes
}

\section{Cite as:}

McLennan, C.L., Becken, S. \& Watt, M. (2016). Learnings from the implementation of a tourism business sustainability programme with six Australian tourism clusters. Journal of Cleaner Production, 111, Part B, 348-357.

\begin{abstract}
Experience shows that the implementation of sustainability programs in practice can be problematic; particularly for small businesses that dominate sectors such as tourism. To overcome a wide range of barriers, a cluster approach to sustainability can provide a clearer path to sustainability, while also offering support and resource and cost savings. Yet there is a dearth of literature highlighting the lessons learnt from sustainability cluster programs. Consequently, the aim of this paper is to investigate learnings arising from EC3 Global's business sustainability program implemented with six tourism clusters involving 138 businesses in Australia in 2008-2010. The cluster data were supplied to the researchers by EC3 Global in the format of reports, regional information, participant lists, starter kits, benchmarking assessments, site assessments, case studies and communication material, and an evaluation of case study success. Using content analysis, the material was systematically classified by broad headings, such as project background, vision, objective, key steps, benefits, opportunities, challenges, risks, outcomes, learnings and next steps. The data were then open coded into key concepts under each broad heading. This research delivers insight into the lessons learned through the implementation of a tourism business sustainability cluster program, including the need for cluster champions and building ownership at the grassroots level.
\end{abstract}

Keywords: learnings, sustainability, tourism cluster, transformation 


\section{Introduction}

The successful movement towards a sustainability platform constitutes a significant transformation or 'phase shift' of social, organisational and technological institutions (Young, 2010). Managing a transformative process, however, is often difficult due to limited knowledge surrounding the transformation process itself (McLennan, Ruhanen, Ritchie \& Pham, 2012). Sustainability programs can act as a tool for transformation when they have a long-term impact that is evidenced through learning (Deutsch, Busby, Orprecio, Bago-Labis \& Cequinã, 2001; Mog, 2004). Indeed, over time, the sustainability movement has resulted in increased recognition within the public and private sectors that there is a need for triple bottom line (economic, social and environmental) measurement and corporate social responsibility (where a business embraces having a positive impact on the environment and society); yet the implementation of sustainability in practice has been problematic (Butler, 1998; Pava, 2008). In a detailed review of the literature, Grimstad (2010) concluded that there is a lack of theory surrounding how businesses perceive their external social and natural environment and the need for sustainability action. In addition, Grimstad (2010) indicated that more research is needed to determine the process businesses take to adopt sustainability, why business driven sustainability initiatives evolve, how businesses implement environmental initiatives and whether organisations cooperate with other organisations to implement initiatives (e.g. through clustering). Ongoing evaluation and learning could enhance the adoption of sustainability by influencing these business processes.

There are a number of well-known benefits and barriers of businesses adopting sustainability initiatives. For example, businesses may adopt sustainable practices for a number of reasons, including ecological and social altruism, compliance with regulations, competitiveness, risk and brand management, profit maximisation, cost reduction, product development and customer pressure (Carasuk, Becken \& Hughey, 2013; Dangelico \& Pujari, 2010; Perez-Batres, Doh, Miller \& Pisani, 2012). Researching what predicts the adoption of sustainability amongst North American hotels and ski resorts, Smerecnik and Andersen (2011) found that sustainability initiatives were adopted if they were simple, if there was support for the adoption of sustainability amongst the business managers, if the business was generally innovative and if the initiative would have business advantages.

Conversely, key barriers and challenges of adopting sustainability initiatives include a lack of internal expertise, high start-up or investment costs, a lack of capital resources, 
competition from other projects, difficulties of integrating sustainable and conventional products, being able to sell at a competitive price, increased price sensitivity, a lack of consumer awareness of environmental initiatives and a lack of communication and coordination amongst organisations (Dangelico \& Pujari, 2010; Granek \& Hassanali, 2006). McNamara and Gibson (2008) found that a key barrier to adopting sustainability is the impact of poor building design and difficulties with retrofitting, combined with the lack of knowledge amongst managers of the financial benefits of adopting sustainable practices. Knowledge generation and sharing are key elements of learning in the arenas of sustainable tourism and cleaner production (Gluch et al., 2013).

Evidence suggests that large tourism organisations have been steadily adopting concepts of sustainable tourism (Clarke, 1997). Indeed, McNamara and Gibson (2008) argue that large tourism businesses are more likely to adopt sustainable practices due to greater levels of available capital, larger specialised workforces that include individuals with environmental backgrounds and longer-term perspectives to cost savings and competitive advantage through environmental initiatives. However, implementing sustainable practices in small and medium sized tourism enterprises (SMEs) has proven to be far more challenging. This has been related to the fact that SMEs typically are limited in financial and human resources and technical capabilities (Chiu, Huang, Lin, Tang, Chen \& Su, 1999), often have a short-term investment perspective (Duarte, Martins \& Alexandre, 2008) and may consider their activities to be less significant or damaging to the environment (McNamara \& Gibson, 2008). Yet SMEs can have significant environmental impacts, particularly collectively due to their large number (Granek \& Hassanali, 2006).

To overcome some of the hurdles associated with being a small business, SMEs are more likely to participate in sustainability programs or clusters. A collective approach assists SMEs to secure funding support and have better access to expertise and assistance (Granek \& Hassanali, 2006). Thus, a cluster approach to sustainability can provide a clearer path to sustainability for SMEs (Allen \& Potiowsky, 2008). Despite the above benefits, many SMEs are not aware that sustainability programs can improve their profitability and efficiency (Granek \& Hassanali, 2006).

Consequently, some literature argues that there is little evidence that the core principles of sustainable tourism have been adopted widely amongst the tourism industry (Fredline, Jago \& Day, 2006), or that the focus has been largely on those initiatives that provide direct marketing or economic benefits (Hall, 1994). In Australia, which is the focus 
of this paper, policy and planning practices of the tourism industry were found to incorporate sustainability concepts (Moyle, McLennan, Ruhanen \& Weiler, 2013); however whether sustainability has transcended to business practice, and whether a cluster approach provides a valuable avenue for sustainability implementation, is still not clear. Thus, there is a need to evaluate current sustainability cluster programs to determine their effectiveness and identify ways to improve their delivery for the future. Consequently, the aim of this paper is to investigate the process of learning arising from EC3 Global's business sustainability program implemented with six tourism clusters, involving 138 businesses in Australia between 2007 and 2012.

\section{Literature Review}

Tourism is inherently a complex system, which is a combination of elements (or subsystems) that together form a complex whole (Johnson, Kast \& Rosenzweig, 1964). Therefore, a tourism system is the conceptual boundary that defines the patterns that construct 'tourism'. Both in the tourism literature and more broadly where other systems are studied, such as in the organisational change, evolutionary economics and the resilience literature, it is recognised that it is possible for systems to learn and generate their own capacity for change (Bagheri \& Hjorth, 2007; Chiang \& Jang, 2008; Hinkin \& Tracey, 1994; Senge, Kleiner, Roberts, Ross \& Smith, 1994). System learning is a process of continually developing rules or beliefs that impact on, or guide, a system (Schianetz, Kavanagh \& Lockington, 2007). Arising from the organisational change literature, transformative system learning theory suggests that a system can 'learn' to adjust and adapt to systematic changes and paradigmatic shifts in its environment. Learning occurs by changing processes, values or institutions to allow greater stability or more directed change (Argyris \& Schon, 1996; Senge, 1990).

Senge (1990) classified organisations as 'living' systems and explored transformative relationships where learning occurs cooperatively. Spitzer (2007) discussed how organisations can control transformation processes through performance measurement and monitoring. Key lessons from the system learning literature include that making strategic mistakes is unavoidable and inherent in the learning process (Kupferberg, 1996; Hallegatte, Ghil, Dumas \& Hourcade, 2008), learning often occurs endogenously (Loye \& Eisler, 1987; Prigogine \& Stengers, 1984), but can also be influenced, directed by or obtained from 
exogenous sources, such as other organisations (Dangelico \& Pujari, 2010). Thus, cooperation between businesses, such as through a cluster approach, might enhance learning opportunities.

Schaefer and Harvey (1998) suggested that an organisational learning approach is required to understand how sustainability is adopted by and disseminated within organisations. The "logics of action”, as described by Bacharach et al. (1996), are the reasons people have for doing certain things; they are generally the normative, cultural, sociological components (including values) of a system. These reasons occur at the individual or group level and generally lead to 'rationalisation of action' and a justification for decisions (Bacharach et al., 1996; Weick \& Roberts, 1993). Bacharach et al. (1996) note that while change is constantly occurring, transformation only occurs when there is change in the logics of action across all sub-groups. Change in these established values and institutions often occur when individual actors recognise that there are gains that can be achieved from the change (DiMaggio \& Powell, 1991). Organisations and businesses are inherently composed of many individuals who make decisions based on their personal knowledge and attitudes. Previous research has called for more research using mixed-level theory that can account for influences and drivers at the macro level (Markus \& Robey, 1988).

Regional sustainability clusters have been identified as complex learning systems (O’Callaghan \& Andreu, 2006). Indeed, it is well recognised in the literature that clusters of co-located businesses support networking, innovation, knowledge creation and learning primarily through sharing practices, processes and experiences (Eisingerich, Bell \& Tracey, 2010). O’Callaghan and Andreu (2006) describe clusters as repositories of knowledge and values that are shared by the member businesses, with knowledge being sourced from individual businesses or from external sources. Two key aspects have been identified in high performing clusters: strong network ties that facilitate knowledge transfer; and, openness to new members and cross-network interactions that provide cluster members with new knowledge, ideas and technologies (Rugman \& D’Cruz, 2002; Eisingerich et al., 2010). Clearly, networks are critical to the knowledge transfer process that facilitates cluster learning (Young, 2010). Yet, O’Callaghan and Andreu (2006) state that there is a "vacuum of literature” on regional clusters’ networking and learning processes.

Similar to cluster learning, the concept of 'Learning Regions' is associated with institutional foundations of competitive advantage at the regional level and centres the region as the locus for knowledge generation and learning (Florida, 1995; Morgan, 1997; Healy \& 
Morgan, 2012). The Learning Regions concept incorporates four key dimensions: a network of learning businesses; a source of learning activity between businesses and other organisations; a set of socio-cultural institutions that facilitate learning and reflexive regional actors who can learn and adapt. Yet gaps are apparent in the Learning Regions literature. Critically, there is little understanding of the inter-regional dimensions of learning and the role of regional governance bodies in the learning process (Hassink \& Lagendijk, 2001; Healy \& Morgan, 2012). To address these gaps, this paper presents the learnings from a cluster approach in the Australian tourism sector.

\section{Methodology}

This research paper is based on data provided by EC3 Global; an international tourism and environmental management and advisory group that provides sustainability solutions for enterprises, destinations and communities. EC3 Global was founded by Australia's Sustainable Tourism Cooperative Research Centre (STCRC) in 1987. One of their key services is to develop and implement programs aimed at achieving sustainability objectives. Between 2007 and 2012, EC3 Global administered six sustainability clusters in Australia aimed at improving the economic, social and environmental sustainability of tourism businesses in the clusters. The organisation collected data on the six tourism sustainability clusters as a part of a regular monitoring programme. This data was collected in order to deliver detailed information on the lessons learnt from the implementation of the tourism business sustainability programme with the six Australian tourism clusters. EC3 Global is a commercial organisation that has undertaken these clusters as a consultancy; however the primary researchers undertaking this analysis were not involved in the consultancy and did not obtain funding to undertake this research.

In the following, the six clusters are described briefly. In 2007, the Regional Tourism Organisation (RTO) associated with the Victorian Cluster was successful in its Australian Tourism Development Program (ATDP) funding application to implement a sustainability program. The purpose of the grant was to facilitate the implementation of a range of initiatives to develop a sustainable future for tourism in the region. At around the same time, tourism businesses in the Tasmanian Cluster had recognised the need and demand from visitors to improve environmental practices in their businesses. Consequently, in 2008 the local RTO secured a Federal Government grant to deliver an environmental sustainability 
program for businesses in the region. The Tasmanian Cluster project therefore set out to respond to the need for businesses to adapt to a carbon constrained economy and to improve efficiencies in energy, water and waste management program.

Queensland Cluster 1 was developed in an attempt to improve sustainability and develop a 'guilt-free' destination to respond to climate change. Building on the success of this cluster, Queensland Cluster 2 was a state-wide program aimed at working with regions, businesses and communities to determine where they were on the path to sustainability and to implement actions to improve sustainable tourism development. Through the ClimateSmart Business Association Program, the Queensland Cluster 3 aimed to develop a Sustainability Program that would enable members to incorporate sustainable best practice into their core business. The Program was designed to allow the Cluster to reduce participants' environmental impacts and meet perceived Corporate Social Responsibility obligations. Modelled on the earlier clusters, Queensland Cluster 4 was formed in 2011 as a Queensland local government area aimed to build a sustainable destination with the aim of supporting global best practise in tourism by partnering with the Queensland Cluster.

The 138 participants in the clusters represented a variety of tourism business types, such as accommodation providers (e.g. villas, bed and breakfasts, hostels and vacation hotels), restaurants, clubs, pubs, breweries, visitor centres, event planners, marinas, retail, day spas, tour operators, cruise vessels, vineyards, administration offices, vehicle hire and attractions. The data relating to the six sustainability clusters was supplied to the researchers by EC3 Global in the format of reports, regional information, participant lists, starter kits, benchmarking assessments, site assessments, case studies and communication material, and an evaluation of case study success.

In total 1,455 documents were supplied with 52 relating to the Victorian Cluster, 84 relating to the Tasmanian Cluster, 971 relating to Queensland Cluster 1, 49 relating to Queensland Cluster 2, 103 relating to Queensland Cluster 3 and 196 relating to Queensland Cluster 4. The majority of the data for this research came from the reports written by EC3 Global (10\% of the material), case studies, background information and surveys on the businesses (6\% of the material), communication material such as newsletters, emails and media releases (6\% of the material), operator workbooks and starter kits ( $6 \%$ of the material), planning, action and policy documents (4\% of the material), member plans and health checks ( $3 \%$ of the material), factsheets (3\% of the material) and other material such as participant lists, information on the initiatives implemented and risk management material ( $2 \%$ of the 
material). The remaining material (61\%) was related to leader information packs, templates, behaviour change models and presentations associated with Queensland Cluster 1, however much of this material did not contribute to the findings of the present study as it was deemed not relevant, although it was thoroughly checked for information that could be included.

Using content analysis, the researchers systematically worked through the relevant data classifying it under broad headings such as project background, vision, objective, key steps, benefits, opportunities, challenges, risks, outcomes, learnings and next steps. With all the programs being managed by EC3 Global, the programs often followed a similar format and identified key information such as benefits, opportunities, challenges, outcomes and learnings, although the information did vary. For example, Queensland Cluster 1 was the only one to have information on leader information packs and presentations, Queensland Cluster 4 was the only cluster with detailed information on initiatives that were implemented and Queensland Cluster 2 was the only cluster with risk management material. The relevant data were extracted from the documents and then entered into excel under each of the broad headings. Under these broad headings the data were then open coded into key concepts and reduced into key themes by collapsing the concepts. If a cluster identified a concept or theme, it was only coded once for each cluster rather than identifying the number of times it was identified by the cluster. This was to minimise the impact of some clusters having more repetitive material than others.

There are a number of limitations to this research that should be acknowledged. Firstly, the only material analysed was that provided to the researchers by EC3 Global. As a result, there may be a bias in terms of whether EC3 Global was able to capture and provide a complete picture of the complex processes occurring within the clusters. In addition, as EC3 Global is a consultant on the project, the reports they have provided may be biased for this reason. In addition, the accuracy of the reports was not within the primary researchers control and thus may have inherent flaws. Lastly, the analysis is biased by the method used to extract the data, as well as the perspectives and bias of the primary researchers.

\section{Results}

\section{Cluster background and implementation}

To provide the context for understanding the learning processes resulting from the cluster programs, there is a need to overview the vision, objectives and key elements of the 
cluster implementation process. Developing a clear vision, objectives and steps to implementation of sustainability were central to the clusters. As a Victorian Cluster Factsheet on preparing sustainability business policy stated: "One of the first steps towards 'sustainability' for a business is to develop an effective Sustainability Policy or a documented commitment to addressing sustainability". Table 1 presents an overview of the vision, objective and key steps that formed the underpinning framework of the sustainability clusters. Generally, the underpinning steps to sustainability that guided all the cluster programs could be identified as: Step 1: Form a cluster; Step 2: Assess current status; Step 3: Plan; Step 4: Facilitate learning; Step 5: Monitor progress. Overtime, it does appear as if the underpinning framework of the sustainability clusters evolved from a three step, to a seven step and eventually to the five step process. Importantly, analysis of the cluster material determined that the Clusters generally recognised the need for radical change to transform to a sustainability platform: “We believe that incremental change will not be sufficient to respond to the enormous challenge of climate change and that we need a transformational change of thinking” [Queensland Cluster 1 - Action Plans prepared by EC3 Global for Tourism Queensland and Queensland Cluster 1].

\section{<INSERT TABLE 1 ABOUT HERE>}

Programme evaluation reports by EC3 Global indicated that, in deciding whether to participate and remain in a sustainability cluster program, the businesses carefully weighed up the benefits versus the costs. To ensure the cluster program was relevant and attractive to tourism businesses, the benefits highlighted in starter kits, information packs and fact sheets were often regarding ways to save money or promote the business. Indeed, the most cited benefit for businesses’ participating in the Cluster programs, both by businesses and program coordinators, was “resource and cost savings” (see Table 2). Competitive advantage was also often cited as a benefit or opportunity of the cluster programs, however, this obviously is only an advantage for the early adopters and as more destinations adopt sustainability this will become less of a benefit of the programs. In almost direct contrast to the key benefit of resource and cost savings, the key challenge of the program was the cost of sustainability initiatives and reaching a 'green wall', where small cost effective solutions have been implemented, but larger initiatives were too expensive. It is widely recognised in the literature that a key barrier to implementing environmental initiatives is the perception that the initial capital investment is too great (Ding \& Pigram, 1996; McNamara \& Gibson, 2008). 
Importantly, aspects of cluster learning featured in the top five cluster identified benefits, opportunities, challenges and outcomes (see bolded points in Table 2).

A key finding from the analysis of the six cluster programs was that, while a reported outcome of the programs was that there was high uptake, there was also high attrition from the programs. Recognising this, a summary report from the Tasmanian Cluster stated that: "While the number of participants has remained relatively constant throughout the program, the businesses in the program have changed.” Similarly, one of the Victorian Cluster's context analysis report noted that businesses "see the benefits of the program, but these clearly do not outweigh the costs.” In addition, the Victorian Cluster and the Queensland Cluster 4 analyses found that a key challenge impacting participants' ability to implement sustainability measures was rising energy and water costs. This suggests that businesses are struggling with a 'lock in effect' where they wish to adopt sustainability measures, but the costs of these measures are too high or there is a lack of capital for investment due to the rising cost of current unsustainable practices.

\section{<INSERT TABLE 2 ABOUT HERE $>$}

\section{Internal Cluster Learning}

Table 3 presents the key program learnings ordered by the most cited across all clusters. The main learning was that there is a need for the cluster programs to focus in on key environmental areas that will have the largest impact and the greatest savings to reinforce positive values and actions. This was followed by encouraging businesses to remain in the program in order for them to see long-term benefits. Rates of adoption and retention could be increased by promoting the simplicity of sustainability programs and ease of adopting sustainability (Smerecnik \& Andersen, 2011). In addition, the analysis of all cluster evaluations highlighted the need for program coordinators or champions to assist businesses in participating in the program (particularly in the early stages of adoption) and to highlight the cost savings that can be achieved through a cluster program.

The cost of the program and initiatives had indeed a significant impact on the outcomes of the cluster program. One report related to the Victorian Cluster noted that "Only a small proportion of small to medium sized businesses have taken substantive action to tackle sustainability as an issue in their business, despite a willingness to engage”. Cluster members tended to limit adoption to a variety of simple, cost effective behavioural and 
technological changes. As a progress summary report for the Tasmanian Cluster found, “Across the board, operators' implemented primarily behavioural changes and small but affordable technological improvements including insulation, composting, energy efficient appliances and low flow showers”. Importantly, it was recognised that working as a cluster can overcome cost barriers by leveraging group or bulk purchases and industry-wide initiatives.

Two key learnings from the clusters were found to contradict each other. While it was argued that there was a need to standardise the program, it was also argued that the program needs to be customised to each business. Mog (2004) argues that sustainable development programs often fail due to the use of the "one size fits all” model, which specifies the initiatives businesses must implement rather than allowing businesses to adopt initiatives of benefit and interest to them. While it may be of benefit to standardise elements of the benchmarking process, maintaining a customised program that can enable businesses to adopt and monitor environmental initiatives relevant to them is critical to ensure businesses remain engaged in the cluster program. This variety also maximises the learnings that can arise from the cluster programs and allows businesses to be innovative and to take their own sustainability path based on their own values.

Lastly, the need to develop training, education and awareness programs to foster learning and the modification of existing organisational values was identified as an important opportunity arising from the EC3 Global's sustainability cluster program. Other ways to develop sustainability expertise amongst cluster members could be through programs aimed at new knowledge transfer such as internships of sustainability students, volunteer or exchange programs amongst the cluster members and invited speakers from other organisations (Young, 2010). Importantly, the clusters recognised the need to up-skill, learn and share their knowledge of sustainability. In this way, sustainability values can be diffused amongst the clusters, as well as the broader community.

\section{<INSERT TABLE 3 ABOUT HERE $>$}

Figure 1 presents the learning loop for sustainability identified from the analysis of the documentation of six sustainability tourism cluster programs. A key element of the learning loop for sustainability programs in tourism is the recognition that the clusters share 
their knowledge with other businesses in the cluster, but also with the community, schools and other industries, which is generally not recognised in the existing learning literature relating to businesses adoption of sustainability. For example, the Victorian Cluster recognised that there is a need to engage with schools and other industries to promote sustainability, while the Queensland Cluster 4 noted the need to work closely with suppliers.

<INSERT FIGURE 1 ABOUT HERE >

\section{Cross-cluster learning processes}

The research on sustainability programmes presented in this paper goes beyond the learnings from individual clusters, but presents a multi-scale approach of cross-cluster learning. Figure 2 presents the interaction cluster learning map that arose from the analysis of all six sustainability clusters. The analysis of the six clusters identified several types of actors and agencies involved in the programs. Firstly, it was possible to identify "cluster champions" and "mentors” who are businesses or actors with a high level of knowledge, interconnectedness with other businesses, and also extra-cluster sources of knowledge that channel new knowledge into the cluster (O’Callaghan \& Andreu, 2006). “Institutional gatekeepers” were also apparent which are organisations such as government, consortia, associations and research institutions that promote knowledge transfer to the businesses in the cluster (O’Callaghan \& Andreu, 2006). Importantly, it was possible to identify "Innovation intermediaries", which are organisations that have evolved as brokers and enablers of innovation networks, information transfer and learning (Howells, 2006; Winch \& Courtney, 2007). Intermediary organisations, like EC3 Global or other knowledge/service providers, can help build credibility and trust in the sustainability program for the cluster and diffuse information among network members, as can institutional gatekeepers, such as government, public research organisations, regional tourism organisations (RTOs) and industry associations (Mesquita, 2007; Eisingerich et al., 2010). It is critical for cluster success that business participants trust their networks as this enables them to obtain and leverage innovations, knowledge, ideas and technology (Granek \& Hassanali, 2006). Thus, intermediary organisations and institutional gatekeepers play a key role in the learning process of clustered businesses (Eisingerich et al., 2010). 
O’Callaghan and Andreu (2006) identified that business type varies, noting that some can be "External stars" - businesses that are highly interconnected with external sources of knowledge but have little interaction amongst the cluster - and "Isolated firms" - those that are scarcely interconnected with cluster or external businesses. This cluster analysis identified that the degree of networking, involvement and on-going participation varied amongst each business and cluster. In addition, each business differed in how much assistance they required, with those just starting out on the sustainability route often requiring more assistance, guidance, support and motivation than those already committed to sustainability. As a result, it was possible to also identify "sustainably engaged” businesses and "early adopters".

Importantly, the clusters recognised the need to engage with other industries, the community and the visitors (who are often community members). For example, a context analysis report for the Victorian Cluster recognised that there was an opportunity to "Engage schools and other industries in 'Sustainability Challenges"'. It was proposed that cluster champions could engage with these broader sustainability stakeholders, with the Queensland Cluster 4 final cluster report suggesting “Appointment of a cluster champion to chair ongoing meetings and voice cluster initiatives in community meetings". In addition, the clusters highlighted the need to market and communicate their sustainability initiatives to visitors and the community in general: "While you can deliver some outstanding projects and initiatives on the ground, the cluster programs rely on consumer marketing and communication to be sustainable” [Final Report for Queensland Cluster 1].

Some possible ways to improve the cluster programs include creating dynamic partnerships with research and development institutions, universities and industry associations by including representatives from these organisations in the cluster programs thereby facilitating the transferal of knowledge, best practice and the latest innovations in sustainability (Duarte et al., 2008). In addition, there is an opportunity for inter-cluster meetings to be developed to facilitate the exchange of knowledge between the sustainability clusters.

$<$ INSERT FIGURE 2 ABOUT HERE $>$ 


\section{Conclusion}

This paper offers a case study of six sustainability clusters in Australia that were facilitated by EC3 Global. A key defining difference from the EC3 Global sustainability campaign compared with those previously postulated in the literature was the cluster approach and the focus on knowledge sharing with community and other industries. It has been postulated that learning clusters have a great potential to break free of path dependency and transform to new paradigms (Hassink, 2005). As a result, this research delivers insights into the lessons learned through the implementation of a tourism business sustainability cluster program, including the need for cluster coordinators, enablers, champions and mentors, as well as building ownership at the grassroots level. Therefore, this research supports the premise that individuals in businesses and clusters can "make a difference". Consequently, it is possible to conclude that well-established theories on individual decision making at the micro level could be linked with other theoretical constructs at higher collective levels, such as the macro or meso levels, allowing more insight into values, institutions and learning processes (Felin \& Foss, 2014). Besides the need for individual actors to facilitate adoption of sustainability within a business, this paper finds that there internal and cross-cluster learning occurs, as does dissemination of learnings to other industries and the community. Given these conclusions, future research could develop a micro-macro framework for tourism sustainability that addresses the "clear conflict between collective theorizing and individual-level measurement” (Felin \& Foss, 2014, p. 445).

The literature often argues that resource-users will not self-organise and governments must use regulatory measures to force change. For example, McNamara and Gibson (2008) conclude that voluntary, self-regulating frameworks have resulted in limited gains and poor uptake of environmental initiatives as they simply offer direction but do not enforce environmental practices. Yet, the literature is increasingly providing examples of individuals and businesses investing time and money into achieving sustainability (Ostrom, 2009). In the Learning Regions literature it is increasingly recognised that governance should shift away from traditional administrative and regulatory functions towards enabling and facilitating knowledge exchange (Healy \& Morgan, 2012). However, Granek and Hassanali (2006) argue that SMEs require a mix of regulation and non-regulatory drivers to adopt sustainability.

This research supports the need for both regulation and voluntary programs as cluster participants were willing to be involved in sustainable action, yet these were generally early adopters who were interested in sustainability and regardless there was still a high turnover of 
participants. Therefore, a combination of voluntary sustainability programs combined with regulation would see sustainability adopted more widely and consistently. In addition, supplying more information and enticements to industry to facilitate their voluntary adoption of environmental initiatives could encourage their participation in programs such as the cluster initiatives implemented by EC3 Global (Leiper, 1995; Middleton \& Hawkins, 1994; McNamara \& Gibson, 2008). Adopting a sustainability platform requires organisational transformation and institutional change to modify existing values, a process that is often legitimised and rationalised by government (Zucker, 1987). Therefore, government involvement in the cluster program also provides an indication to businesses that the cluster program is credible and necessary.

Importantly, sustainability clusters need to be on-going and focused on continuous learning and adaption. Sustainability projects that are short-term or focused on one-off improvements often lose their impact with businesses reverting back to old behaviours or learnings being lost once the programme is finished (Esman \& Herring, 2003; Mog, 2004). It should be acknowledged that many project participants become change agents and advocates for sustainability by facilitating the implementation of sustainability principles they learnt during the cluster program within their business. These participants will continue to transfer their learned knowledge and implement sustainability well beyond the end of the cluster program, thereby incrementally contributing to long-term transformation towards a sustainability platform.

\section{Acknowledgements}

The researchers would like to acknowledge EC3 Global for providing access and insights into the Cluster data.

\section{References}

Allen, J. H., \& Potiowsky, T. (2008). Portland's Green Building Cluster Economic Trends and Impacts. Economic Development Quarterly, 22(4), 303-315.

Argyris, C., \& Schön, D. (1996). Organizational learning II: Theory, method, and practice. Reading, MA: Addison-Wesley. 
Bacharach, S. B., Bamberger, P., \& Sonnenstuhl, W. J. (1996). The Organizational Transformation Process: The Micropolitics of Dissonance Reduction and the Alignment of Logics of Action. Administrative Science Quarterly, 41(3), 477-506.

Bagheri, A., \& Hjorth, P. (2007). Planning for sustainable development: a paradigm shift towards a process-based approach. Sustainable Development, 15, 83-96.

Butler, R., W. (1998). Sustainable tourism: Looking backwards in order to progress? In C. M. Hall \& A. A. Lew (Eds.), Sustainable Tourism: A Geographical Perspective (pp. 2534). Harlow, UK: Longman.

Carasuk, R., Becken, S., \& Hughey, K. F. D. (2013). Exploring Values, Drivers, and Barriers as Antecedents of Implementing Responsible Tourism. Journal of Hospitality \& Tourism Research, DOI: 10.1177/1096348013491607.

Chiang, C.-F., \& Jang, S. (2008). The antecedents and consequences of psychological empowerment: the case of Taiwan's Hotel Companies. Journal of Hospitality and Tourism Research, 32(1), 40-61.

Chiu, S., Huang, J. H., Lin, C., Tang, Y., Chen, W., \& Su, S. (1999). Applications of a corporate synergy system to promote cleaner production in small and medium enterprises. Journal of Cleaner Production, 7, 351-358.

Clarke, J. (1997). A framework of approaches to sustainable tourism. Journal of Sustainable Tourism, 5(3), 224-233.

Dangelico, R. M., \& Pujari, D. (2010). Mainstreaming green product innovation: why and how companies integrate environmental sustainability. Journal of Business Ethics, 95(3), 471-486.

Deutsch, W. G., Busby, A. L., Orprecio, J. L., Bago-Labis, J., \& Cequiña, E. (2001). Community-based water quality monitoring: from data collection to sustainable management of water resources. Challenges of Natural Resource Management in a Rapidly Developing Economy: A Case Study from a Philippine Watershed, Los Baños: Philippine Council on Agricultural Research, Natural Resources and Development, 138-160.

DiMaggio, P., \& Powell, W. W. (1991). The iron cage revisited: Institutional isomorphism and collective rationality in organizational fields. In P. DiMaggio \& W. W. Powell (Eds.), The new institutionalism in organizational analysis (pp. 63-82). Chicago: The University of Chicago Press.

Ding, P., \& Pigram, J. (1996). An approach to monitoring and evaluating the environmental performance of Australian beach resorts. Australian Geographer, 27(1), 77-86.

Duarte, A. P., Martins, P., \& Alexandre, J. (2008). Pro-active behaviour induction by integration of sustainability in business strategic movement: INOVE project case study. Journal of Cleaner Production, 16, 1127-1132.

Eisingerich, A. B., Bell, S. J., \& Tracey, P. (2010). How can clusters sustain performance? The role of network strength, network openness, and environmental uncertainty. Research Policy, 39, 239-253.

Esman, M. J., \& Herring, R. J. (2003). Carrots, sticks, and ethnic conflict: rethinking development assistance. United States of America: University of Michigan press.

Florida, R. (1995). Towards the learning region. Futures, 27(5), 527-536. 
Fredline, L., Jago, L., \& Day, S. (2006). State of the tourism industry. Gold Coast: Sustainable Tourism Cooperative Research Centre and the National Tourism Alliance.

Gluch, P., Johansson, K. \& Räisänen, C. (2013). Knowledge sharing and learning across community boundaries in an arena for energy efficient buildings. Journal of Cleaner Production, 48, 232-240.

Granek, F., \& Hassanali, M. (2006). The Toronto region sustainability program: insights on the adoption of pollution prevention practices by small to medium-sized manufacturers in the Greater Toronto Area (GTA). Journal of Cleaner Production, 14, 572-579.

Grimstad, S. (2010). Developing a framework for examining business-driven sustainability initiatives with relevance to wine tourism clusters. International Journal of Wine Business Research, 23(1), 62-82.

Hall, C. M. (1994). Tourism and Politics, Power and Place. London: Bellhaven Press.

Hallegatte, S., Ghil, M., Dumas, P., \& Hourcade, J.-C. (2008). Business cycles, bifurcations and chaos in a neo-classical model with investment dynamics. Journal of Economic Behaviour \& Organisation, 67(1), 57-77.

Hassink, R., \& Lagendijk, A. (2001). The dilemmas of interregional institutional learning. Environment and Planning C, 19(1), 65-84.

Healy, A., \& Morgan, K. (2012). Spaces of Innovation: Learning, Proximity and the Ecological Turn. Regional Studies, 46(8), 1041-1053.

Henriques, A. (2007). Corporate truth: The limits to transparency. London: Earthscan.

Hess, D. (2008). The three pillars of corporate social reporting as new governance regulation: Disclosure, dialogue and development. Business Ethics Quarterly, 18(4), 447-482.

Hinkin, T. R., \& Tracey, J. B. (1994). Transformational Leadership in the Hospitality Industry. Journal of Hospitality and Tourism Research, 18(1), 49-63.

Howells, J. (2006). Intermediation and the role of intermediaries in innovation. Research Policy, 35(5), 715-728.

Jago, L., Fredline, L., \& Cooper, C. (2003). Bill Faulkner: Progressing Tourism Research and Beyond. In L. Fredline, L. Jago \& C. Cooper (Eds.), Progressing Tourism Research: Bill Faulkner. Clevedon: Channel View Publications.

Kupferberg, F. (1996). Strategic Learning: East Germany as a 'Model Case' for Transformation Theory. International Sociology, 11(4), 457-479.

Leiper, N. (1995). Tourism Management. Melbourne: RMIT Publishing.

Loye, D., \& Eisler, R. (1987). Chaos and Transformation: Implications of non-equilibrium theory for social science and society. Behavioral Science, 32, 53-65.

McLennan, C., Ruhanen, L., Ritchie, B., \& Pham, T. (2012). Dynamics of Destination Development: Investigating the application of Transformation Theory. Journal of Hospitality and Tourism Research, 36(2), 164-190.

McNamara, K. E., \& Gibson, C. (2008). Environmental Sustainability in Practice? A macroscale profile of tourist accommodation facilities in Australia's coastal zone. Journal of Sustainable Tourism, 16(1), 85-100. 
Mesquita, L. F. (2007). Starting over when the bickering never ends: rebuilding aggregate trust among clustered firms through trust facilitators. Academy of Management Review, 32, 72-91.

Middleton, V., \& Hawkins, R. (1994). Practical environmental policies in travel and tourism: Part 2 airlines, tour operators and destinations. EIU Travel and Tourism Analyst (pp. 83-97). London: The Economist Intelligence Unit.

Mog, J. M. (2004). Struggling with Sustainability - A comparative framework for evaluating sustainable development programs. World Development, 32(12), 2139-2160.

Morgan, K. (1997). The learning region: institutions, innovation and regional renewal. Regional Studies, 31(5), 491-503.

Moyle, B. D., McLennan, C.-l. J., Ruhanen, L., \& Weiler, B. (2013). Tracking the concept of sustainability in Australian tourism policy and planning documents. Journal of Sustainable Tourism, DOI: 10.1080/09669582.2013.839694.

O'Callaghan, R., \& Andreu, R. (2006). Knowledge Dynamics in Regional Economies: A Research Framework. Paper presented at the 39th Hawaii International Conference on System Sciences, Hawaii.

Ostrom, E. (2009). A general framework for analyzing sustainability of social-ecological systems. Science, 325, 419-422.

Pava, M. L. (2008). Why corporations should not abandon social responsibility. Journal of Business Ethics, 83(4), 805-812.

Perez-Batres, L. A., Doh, J. P., Miller, V. V., \& Pisani, M. J. (2012). Stakeholder pressures as determinants of CSR strategic choice: Why do firms choose symbolic versus substantive self-regulatory codes of conduct? Journal of Business Ethics, 110(2), 157172.

Prigogine, I., \& Stengers, I. (1984). Order Out of Chaos. Man's New Dialogue with Nature. Boulder, Colorado: Shambhala Publications.

Rugman, A. M., \& D'Cruz, J. R. (2002). Multinationals as flagship firms: regional business networks. Management International Review, 42, 347-352.

Schaefer, A., \& Harvey, B. (1998). Stage models of corporate greening: a critical evaluation. Business Strategy and the Environment, 7(3), 109-123.

Schianetz, K., Kavanagh, L., \& Lockington, D. (2007). The Learning Tourism Destination: The potential of a learning organisation approach for improving the sustainability of tourism destinations. Tourism Management, 28, 1485-1496.

Senge, P. M. (1990). The Fifth Discipline: The Art of Practice of the Learning Organisation. New York: Currency Doubleday.

Senge, P. M., Kleiner, A., Roberts, C., Ross, R. B., \& Smith, B. S. (1994). The fifth discipline field book: Strategies and tools for building a learning organisation. London: Nicholas Brealey Publishing.

Sharpley, R. (2009). Tourism development and the environment: Beyond sustainability? London: Earthscan.

Smerecnik, K. R., \& Andersen, P. A. (2011). The diffusion of environmental sustainability innovations in North American hotels and ski resorts. Journal of Sustainable Tourism, 19(2), 171-196. 
Spitzer, D. R. (2007). Transforming Performance Measurement: Rethinking the way we measure and drive organisational success. New York: American Management Association (AMACOM).

Weick, K. E., \& Roberts, K. H. (1993). Collective Mind in Organizations: Heedful Interrelating on Flight Decks. Administrative Science Quarterly, 38(3), 357-381.

Winch, G., \& Courtney, R. (2007). The organization of innovation brokers: an international review. Technology analysis and strategic management, 19(6), 747-763.

Young, R. F. (2010). The greening of Chicago: environmental leaders and organisational learning in the transition towards a sustainable metropolitan region. Journal of Environmental Planning and Management, 53(8), 1051-1068.

Zucker, L. G. (1987). Institutional theories of organization. Annual Review of Sociology, 13, 443-464. 
Table 1. Project vision, objective and key steps by Cluster

\begin{tabular}{|c|c|c|c|}
\hline Cluster & Vision & Program Objective & Program Key Steps \\
\hline VIC & $\begin{array}{l}\text { To design \& implement a } \\
\text { sustainability program that engages } \\
\text { the entire community in the region. }\end{array}$ & $\begin{array}{l}\text { To develop competitive advantage } \\
\text { for the cluster in attracting the } \\
\text { higher yielding 'Socially } \\
\text { Responsible Traveller'; to provide } \\
\text { assistance to businesses \& } \\
\text { communities in taking the first step } \\
\text { along the pathway to sustainability; } \\
\text { \& to assist the region to overcome } \\
\text { identified key challenges including } \\
\text { seasonality \& building a strong \& } \\
\text { unique destination brand. }\end{array}$ & $\begin{array}{l}\text { 1. Undertake consumer research } \\
\text { into sustainable tourism } \\
\text { 2. Develop \& implement } \\
\text { stakeholder education, marketing of } \\
\text { sustainability in region \& a } \\
\text { Sustainable Tourism Code of } \\
\text { Conduct. Select environmental } \\
\text { performance measures. } \\
\text { 3. Develop a media plan \& } \\
\text { traveller's guide. Investigate } \\
\text { international partnerships \& off } \\
\text { peak visitation strategies. }\end{array}$ \\
\hline TAS & $\begin{array}{l}\text { To imbed good practice in business } \\
\text { operations \& achieve accreditation } \\
\text { across the region; obtain a } \\
\text { competitive advantage for the } \\
\text { cluster; improve communication } \\
\text { between cluster members; be seen } \\
\text { as a leader in sustainability; provide } \\
\text { a template for other communities to } \\
\text { learn from \& follow; transfer } \\
\text { environmental best practice to other } \\
\text { sectors; boost word of } \\
\text { mouth/market awareness; enable } \\
\text { visitors to obtain 'peace of mind'. }\end{array}$ & $\begin{array}{l}\text { To respond to increasing demands } \\
\text { by consumers \& suppliers for } \\
\text { tourism businesses to demonstrate } \\
\text { their adoption of environmental } \\
\text { practices. Delivery of business } \\
\text { skills required for businesses to } \\
\text { undertake a tourism environmental } \\
\text { audit \& increase their business } \\
\text { efficiency, improve } \\
\text { entrepreneurship \& potentially } \\
\text { improve profit levels from better } \\
\text { environmental, social \& economic } \\
\text { practices. }\end{array}$ & $\begin{array}{l}\text { 1. Select participants } \\
\text { 2. Train local mentors } \\
\text { 3. Conduct sustainability workshop } \\
\text { \& training } \\
\text { 4. Undertake baseline assessments } \\
\text { 5. Undertake reporting with } \\
\text { ongoing support/encouragement } \\
\text { from Cluster mentors } \\
\text { 6. Facilitate review workshop with } \\
\text { participants \& stakeholders } \\
\text { 7. Analyse cluster progress }\end{array}$ \\
\hline QLD1 & $\begin{array}{l}\text { To be recognised internationally \& } \\
\text { domestically as a sustainable } \\
\text { tourism destination, where the very } \\
\text { assets that attract visitors to the } \\
\text { region are managed for the } \\
\text { enjoyment of future generations. }\end{array}$ & $\begin{array}{l}\text { To assist Queensland's tourism } \\
\text { regions to become sustainable } \\
\text { tourism destinations \& } \\
\text { communities. }\end{array}$ & $\begin{array}{l}\text { 1. Form a cluster of businesses } \\
\text { 2. Undertake baseline } \\
\text { assessments/site audits } \\
\text { 3. Conduct regional audit/health } \\
\text { check } \\
\text { 4. Conduct sustainability workshop } \\
\text { 5. Prepare an action plan }\end{array}$ \\
\hline QLD2 & $\begin{array}{l}\text { To be recognised internationally \& } \\
\text { domestically as a sustainable } \\
\text { tourism destination, where the very } \\
\text { assets that attract visitors to the } \\
\text { region are managed for the } \\
\text { enjoyment of future generations. }\end{array}$ & $\begin{array}{l}\text { To provide mentoring support for } \\
\text { businesses \& boost the already } \\
\text { established cluster of businesses } \\
\text { locally who care about } \\
\text { sustainability. }\end{array}$ & $\begin{array}{l}\text { 1. Guide businesses through a } \\
\text { sustainability framework } \\
\text { 2. Conduct sustainability workshop } \\
\text { 3. Undertake baseline assessments } \\
\text { \& develop action plans } \\
\text { 4. Conduct R.O.I. workshop } \\
\text { 5. Develop cluster report }\end{array}$ \\
\hline QLD3 & $\begin{array}{l}\text { To position the Cluster as a leader } \\
\text { in delivering practical sustainability } \\
\text { outcomes to inspire \& support our } \\
\text { community. }\end{array}$ & $\begin{array}{l}\text { To set industry benchmarks for } \\
\text { sustainable operation, position the } \\
\text { Cluster as a leader in innovative } \\
\text { practice, provide leadership in } \\
\text { sustainability \& develop a } \\
\text { framework for future } \\
\text { implementation of sustainability } \\
\text { programs. }\end{array}$ & $\begin{array}{l}\text { 1. Participant selection } \\
\text { 2. Measuring \& monitoring } \\
\text { 3. Site surveys \& action plans } \\
\text { 4. Benchmarks \& Key Performance } \\
\text { Indicators }\end{array}$ \\
\hline QLD4 & $\begin{array}{l}\text { To be renowned for sustainable } \\
\text { management of the regions natural } \\
\text { \& built environment, its sense of } \\
\text { self confidence, the vibrancy \& } \\
\text { depth of its service economy, the } \\
\text { well-being of its community \& its } \\
\text { unique sense of place as a thriving } \\
\text { \& dynamic resort destination. }\end{array}$ & $\begin{array}{l}\text { To assist Queensland's tourism } \\
\text { regions to become sustainable } \\
\text { tourism destinations \& } \\
\text { communities. }\end{array}$ & $\begin{array}{l}\text { 1. Identify \& train cluster } \\
\text { champions } \\
\text { 2. Conduct sustainability workshop } \\
\text { 3. Undertake site audits } \\
\text { 4. Develop an action plan \& cluster } \\
\text { workshop }\end{array}$ \\
\hline
\end{tabular}


Table 2. Top Five Cluster Identified benefits, Opportunities, Challenges, Risks and Outcomes of the Sustainability Cluster Programs

\begin{tabular}{|c|c|}
\hline Benefits & $\begin{array}{ll}\text { 1. } & \text { Resource \& cost savings (cited by } 6 \text { clusters) } \\
\text { 2. } & \text { Marketing, positioning \& promotional support (cited by } 5 \text { clusters) } \\
\text { 3. } & \text { Community engagement \& support (cited by } 4 \text { clusters) } \\
\text { 4. } & \text { Recognition by government (cited by } 4 \text { clusters) } \\
\text { 5. } & \text { Education, guidance \& mentoring through program (cited by } 4 \text { clusters) }\end{array}$ \\
\hline Opportunities & $\begin{array}{l}\text { 1. Cluster branding \& promotion that links with other sustainability programs \& RTO marketing (cited by } 4 \text { clusters) } \\
\text { 2. Promote 'green' credentials \& position cluster as an innovator to gain competitive advantage (cited by } 4 \text { clusters) } \\
\text { 3. Foster learning through information sharing, training, education \& engagement (cited by } 3 \text { clusters) } \\
\text { 4. Corporate social responsibility: establish 'culture of sustainability' \& enable businesses to make a difference (cited by } 3 \\
\text { clusters) } \\
\text { 5. Implement sustainability initiatives \& vary initiatives by region to create a point of difference (cited by } 3 \text { clusters) }\end{array}$ \\
\hline Challenges & $\begin{array}{l}\text { 1. Cost of sustainability initiatives/reaching 'green wall' (cited by } 5 \text { clusters) } \\
\text { 2. Changing external environment i.e. consumer trends, economic environment, regulation due to climate change (cited by } 5 \\
\text { clusters) } \\
\text { 3. Perceived internal structural constraints to adopting sustainability i.e. reliance on air-conditioning, lack of space for rain water } \\
\text { tanks, difficulty accessing local/sustainable products, hard to get started, rewards of sustainability take a long time. time, staff } \\
\text { \& monetary constraints (cited by } 5 \text { clusters) } \\
\text { 4. Lack of information/confusion about new/emerging sustainability solutions (cited by } 4 \text { clusters) } \\
\text { 5. Lack of business participation \& commitment (cited by } 4 \text { clusters) }\end{array}$ \\
\hline Risks & $\begin{array}{l}\text { 1. } \text { Climate change (cited by } 3 \text { clusters) } \\
\text { 2. The impact of disasters (cited by } 2 \text { clusters) } \\
\text { 3. Declining travel (cited by } 2 \text { clusters) } \\
\text { 4. } \quad \text { Increasing operational/travel costs (cited by } 2 \text { clusters) } \\
\text { 5. } \quad \text { Being branded as "greenwash" (cited by } 2 \text { clusters) }\end{array}$ \\
\hline Outcomes & $\begin{array}{l}\text { 1. Completion of program requirements (i.e. health check surveys, business' carbon foot-printing, site visits, reports) (cited by } 5 \\
\text { clusters) } \\
\text { 2. 'Green' initiatives implemented often leveraging group/bulk purchasing opportunities \& industry-wide initiatives (cited by } 5 \\
\text { clusters) } \\
\text { 3. Businesses, staff, mentors \& champions received training, education, mentoring \& empowerment (cited by } 4 \text { clusters) } \\
\text { 4. Formation of clusters (i.e. to deliver innovative visitor information, promotion \& engagement programs) (cited by } 3 \text { clusters) } \\
\text { 5. Raised awareness \& advocacy for environmental best practice i.e. with guests \& businesses (cited by } 3 \text { clusters) }\end{array}$ \\
\hline
\end{tabular}

Note: Bolded points are areas relevant to learning 


\section{Table 3. Key program learnings ordered by most cited}

1. Focus in on key environmental areas that will have largest impact \& the greatest savings/group purchase rates (reduces time burden, increases participation, reduces costs, improves customer satisfaction, program viewed as value) (cited by 5 clusters)

2. Encourage businesses to remain in program (high attrition) - program needs to be voluntary \& free, requiring limited funds to run \& manage, identify \& select regional champions to push program (often based on commitment/influence), need to build ownership at the grass roots level, identify business sustainability enabler i.e. responsibility for environmentally responsible practices often rests with just one individual in the organisation who is passionate about sustainability (cited by 5 clusters)

3. Educate \& train owners, staff, champions \& visitors on sustainability \& cluster initiatives - develop sector specific sustainability training/awareness programs (builds capacity \& support for program) (cited by 4 clusters)

4. Government support, grants, training, marketing \& initiatives for clusters is required for program to be successful \& reach a point of sustainability (cited by 4 clusters)

5. Implement \& give credit for other initiatives even if they are not quantifiable (i.e. carbon offsetting, community education, cluster processes, reduce dependence on power grid, organic waste disposal) (cited by 4 clusters)

6. Develop strategies \& processes for implementation i.e. Cluster Action, Code of Conduct, Communications \& Marketing Plan - link with other sustainability/marketing programs/initiatives (i.e. RTO marketing), package cluster's "carbon light" products \& promote region as "Green" but take care to avoid 'greenwash' (cited by 4 clusters)

7. Improve, standardise \& promote benchmarking system (i.e. account for differences between large \& small businesses, different sustainability programs \& extreme events such as renovations, disasters \& outsourcing; measure performance against industry standards/on a per patron basis \& promote 'you can't manage what you don't measure') (cited by 4 clusters)

8. Consolidate \& disseminate information about the work undertaken to date i.e. facilitate cluster meetings/forums/workshops (i.e. to share knowledge \& bridge gaps between businesses \& government/RTO), use cluster newsletter \& website to disseminate information (e.g. updates on program achievements/actions, develop \& promote CSR information, 'green tips', fact sheets) (cited by 3 clusters)

9. Structure program into different levels of commitment/participation \& customise to each business (i.e. business diversity, need to recognise those who are already very sustainable, develop customised site audit templates) (cited by 3 clusters)

10. Businesses to undertake research before developing \& implementing sustainability strategy (cited by 2 clusters)

11. Business processes or building design/management often a barrier i.e. lack of sub-metering, need to consider building design, need to engage building owners/neighbours in sustainability initiatives, businesses need to learn how to use their technology efficiently \& manage peak demand spikes, board approval processes slow down implementation (cited by 2 clusters)

12. Review programs \& resources on an annual basis (i.e. develop an annual Environmental Performance Report, review procurement policy for sustainably sourced \& carbon neutral products) (cited by 2 clusters)

13. Difficulty obtaining regional data on energy, water \& waste i.e. reporting districts vary, not managed by Council, confidentiality of information, develop partnerships for the sharing of aggregated environmental data (cited by 2 clusters)

14. Substantial time is required to set up program, engage businesses in program (at least 6 months) \& for them to complete tasks i.e. implement programs outside of peak seasons (cited by 1 cluster)

15. Program coordinators are key to business involvement i.e. need to have face-to-face contact, knowledge of local issues \& be knowledgeable of 'Starter Kits' to get businesses on-board, need for program coordinators to help businesses initially estimate \& input their benchmarking data to reduce them being overwhelmed \& increase their enthusiasm for the program (cited by 1 cluster)

16. Guests respond positively to \& participate in businesses environmental initiatives (cited by 1 cluster) 


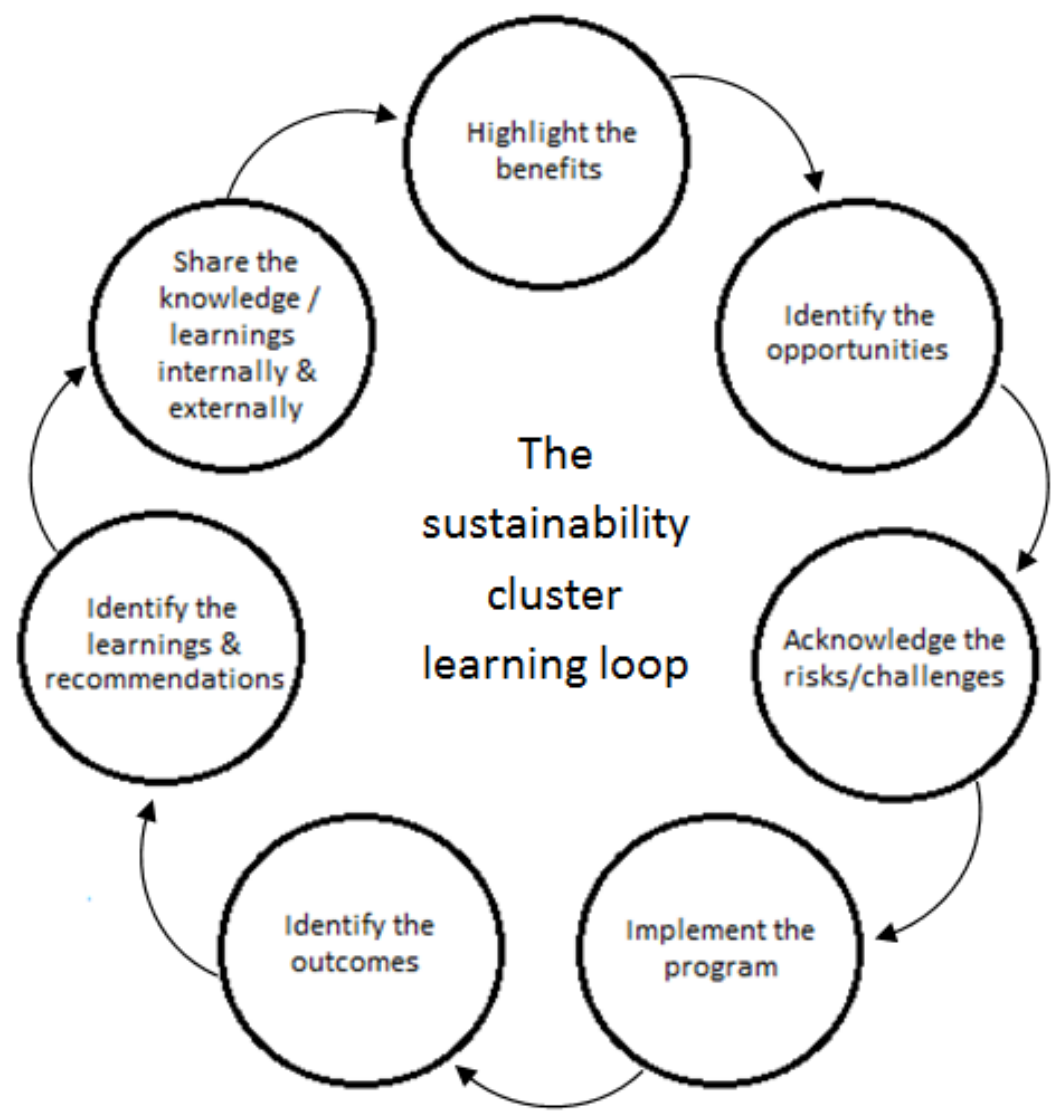

Figure 1. The learning loop for sustainability cluster programs in tourism 


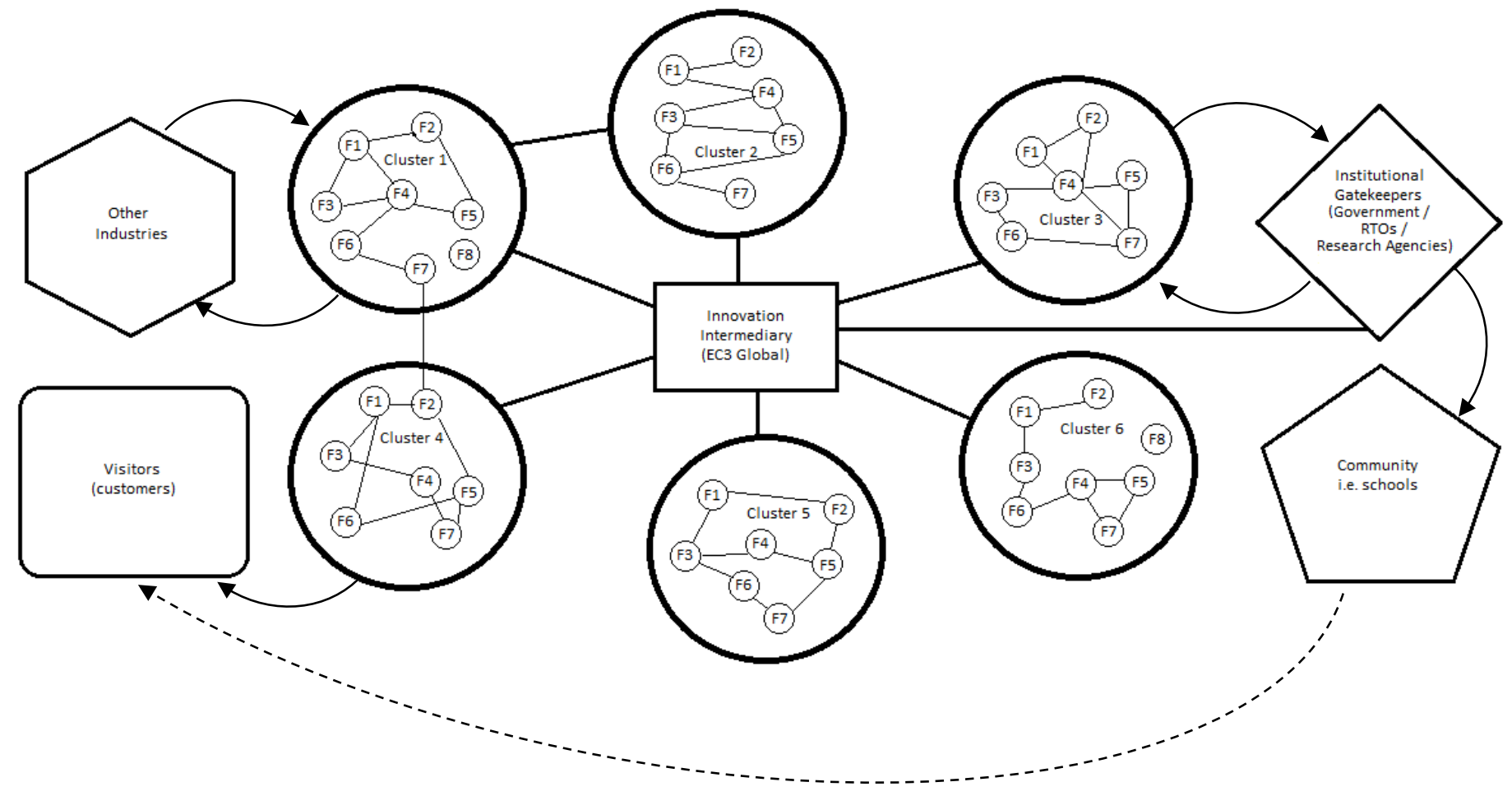

Figure 2. The Interaction Cluster Learning Map 